\title{
A New Three-Phase Doubly Salient Permanent Magnet Machine for Wind Power Generation
}

\author{
Ying Fan, Student Member, IEEE, K. T. Chau, Senior Member, IEEE, and Ming Cheng, Senior Member, IEEE
}

\begin{abstract}
This paper presents a new three-phase 12/8-pole doubly salient permanent-magnet (DSPM) machine for application to wind power generation. The key is to design and analyze the proposed DSPM generator, namely, the design of a new machine structure to achieve high power density and high robustness and the device of system operation to attain high efficiency. By using finite element analysis, the static characteristics of the proposed generator are given. Hence, the evaluation of system performances is conducted by computer simulation. Experimentation is also given to verify the validity of the proposed DSPM generator.
\end{abstract}

Index Terms-Doubly salient motors, permanent-magnet (PM) machines, wind power generation.

\section{INTRODUCTION}

W ITH the ever increasing concerns on energy crisis and environmental protection, the development of renewable energy resources has taken an accelerated pace. Wind power is one of the most viable renewable energy resources. For wind power generation, the core element is the wind power generator. The conventional generators, such as the synchronous generator and the induction generator, are mainly designed for constant-speed turbine operation so that they are inefficient or even ill suited for variable-speed wind-turbine operation. Therefore, an efficient generator particularly for wind power generation is highly desirable. In [1], the switched reluctance (SR) machine was proposed for wind power generation because of its advantages of brushless nature, high robustness, and high reliability. In [2], the doubly salient permanent magnet (DSPM) machine, incorporating the structure of SR machines and the use of permanent magnet (PM) materials, was proposed to work as a single-phase generator. Recently, it has been revealed that the polyphase DSPM machine can offer higher efficiency, higher power density, and better controllability than its counterparts, including the induction and the SR machines [3], [4].

Paper IPCSD-05-082, presented at the 2004 Industry Applications Society Annual Meeting, Seattle, WA, October 3-7, and approved for publication in the IEEE TRANSACTIONS ON INDUSTRY APPLICATIONS by the Electric Machines Committee of the IEEE Industry Applications Society. Manuscript submitted for review February 1, 2005 and released for publication November 4, 2005. This work was supported by the Research Grants Council of Hong Kong under Grant HKU7111/05E.

Y. Fan and K. T. Chau are with the Department of Electrical and Electronic Engineering, The University of Hong Kong, Hong Kong (e-mail: yfan@eee. hku.hk; ktchau@eee.hku.hk).

M. Cheng is with the Department of Electrical Engineering, Southeast University, Nanjing 210096, China (e-mail: mcheng@ seu.edu.cn).

Digital Object Identifier 10.1109/TIA.2005.861910

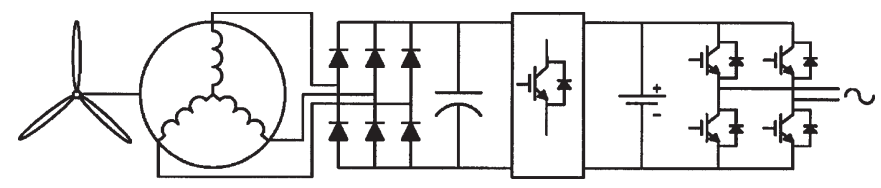

Fig. 1. System configuration.

Moreover, compared to induction and SR generators, the DSPM generator can produce more power from the same geometry [5] and can offer higher efficiency [6]. By using a sizing equation, it is shown that the DSPM generator has $40 \%$ more power production capability than an induction generator based on the same speed, volume, and electric loading [7]. Furthermore, because of the absence of PM materials in the rotor, the DSPM generator takes the advantages of higher robustness and higher reliability than other PM brushless generators. On the other hand, by using cubic splines, nonlinear modeling of the DSPM generator is developed [8]. Thus, the instantaneous inductance and the no-load electromotive force (EMF) can be accurately determined.

The purpose of this paper is to propose a new three-phase 12/8-pole DSPM machine particularly for wind power generation. This DSPM generator can offer higher efficiency, higher power density, and better controllability than both the induction and SR generators. The key is to design a new machine structure and to devise the system operation. In Section II, the system configuration and the speed constraint of a 12/8-pole DSPM wind generator will be described. Section III will be devoted to the machine design, including the topological selection and the electromagnetic analysis. The finite-element method (FEM) is applied to analyze the static characteristics of the generator. The system modeling and simulation will be discussed in Section IV. The implementation and the experimental verification will be given in Section V. Finally, conclusions will be drawn in Section VI.

\section{System Configuration And Speed Constraint}

Fig. 1 shows the system configuration, which consists of a wind turbine for capturing wind power, a three-phase DSPM generator for electromechanical energy conversion, a threephase full-bridge rectifier for ac-dc conversion, a buck converter for dc voltage regulation, a battery for electrical energy storage, and a single-phase or three-phase inverter for $\mathrm{dc}-\mathrm{ac}$ conversion.

The rated speed of the DSPM generator, which dictates the whole size of the generator, can be determined by the 
wind energy equation developed by a wind turbine. The net electrical energy produced by a wind-turbine system depends on the speed of the wind passing through its swept area and the efficiencies of its components. In [9], for a horizontal-axis wind turbine, the actual mechanical output power $P_{\text {mech }}$ is typically expressed as

$$
P_{\text {mech }}=\frac{1}{2} C_{p} \rho \nu_{w}^{3} A
$$

where $C_{p}$ is the coefficient of wind power with a typical value of 0.4 or below, $\rho$ is the air density, $\nu_{w}$ is the wind velocity, and $A$ is the swept area of wind-turbine rotor. The value of $C_{p}$ varies with $\beta$, which is the ratio of the wind turbine's blade tip speed to the wind speed

$$
\beta=\frac{\omega R}{\nu_{w}}
$$

where $R$ is the radius of blades and $\omega$ is the angular speed of the wind-turbine shaft. When $\beta$ takes the specific value $\beta_{\max }$, the characteristic of $C_{p}$ has a single maximum [10]. It is obvious that the shaft speed should change with the wind speed to extract maximum power from the wind. When the turbine is running at $\beta_{\max }$, the output power can be expressed as

$$
P_{\text {mech }}=\frac{1}{2}\left(C_{p \max } \pi R^{2} \rho\right) \nu_{w}^{3} .
$$

The item $\left(C_{p \max } \pi R^{2} \rho\right)$ is a constant with a given wind turbine. Thus, the output power varies with the cubic wind speed, and $P_{\text {mech }}$ can be rewritten as

$$
P_{\text {mech }}=\frac{1}{2}\left(\frac{C_{p \max } \pi R^{5} \rho}{\beta_{\max }^{3}}\right) \omega^{3} .
$$

It should be noted that the rotor speed of a small variable-speed direct-drive wind generator is typically below $1000 \mathrm{r} / \mathrm{min}$.

\section{MAChine DeSIGN}

\section{A. Topological Selection}

There is a wide range of possible combinations of phase numbers as well as stator and rotor-pole numbers that can be chosen for DSPM generator design. In accordance with the basic operation principle of the DSPM generator, the general relationship among $N_{s}, N_{r}$, and $m$ is given by

$$
\left\{\begin{array}{l}
N_{s}=2 m k \\
N_{r}=N_{s} \pm 2 k
\end{array}\right.
$$

where $N_{s}$ and $N_{r}$ are the numbers of stator and rotor poles, respectively; $m$ is the number of phases; and $k$ is a positive

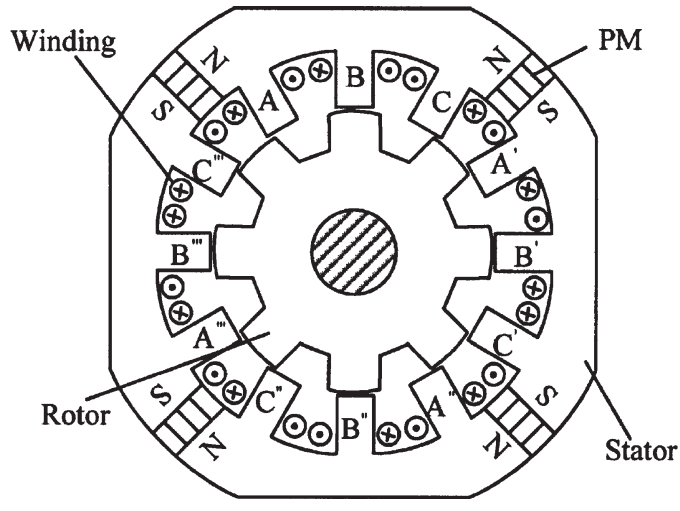

Fig. 2. Three-phase 12/8-pole DSPM generator.

integer. When the generator runs at the speed of $n$, the frequency of no-load EMF is given by

$$
f=\frac{N_{r} n}{60} .
$$

To minimize the iron losses in poles and yokes, the number of rotor poles is usually less than that of stator poles. For example, $N_{s} / N_{r}=8 / 6$ and $12 / 8$ are possible configurations of the DSPM generator. Comparing these two types of machines, which run at the same speed, the 12/8-pole machine has the advantages over the 8/6-pole machine, namely, smaller number of phases, higher power density, and simpler system configuration and control.

The DSPM generator is the key to this wind-powergenerating system. Fig. 2 shows the cross section of the proposed three-phase 12/8-pole DSPM generator. It has 12 salient poles in the stator and 8 salient poles in the rotor. There are four pieces of PM material, namely, the neodymium-iron-boron $(\mathrm{Nd}-\mathrm{Fe}-\mathrm{B})$ with a linear demagnetizing characteristic, placed inside the stator yoke to provide field excitation. The two coils on the diametrically opposite stator poles are connected in series to form a winding, and the two relevant windings are also connected in series to form a phase winding in the stator. Since there are no PMs, brushes, nor windings in the rotor; the generator offers a very simple rotor structure and low rotor inertia.

There are two types of rotor for selection: one is the unskewed rotor, which produces square waves of no-load EMF and current, and the other is the skewed rotor, which produces sinusoidal waves of no-load EMF and current. The one offering a higher power density will be selected for this DSPM generator.

For a machine with sinusoidal waveforms, when its no-load EMF $e_{s}$ and phase current $i_{s}$ are in phase, the average power $P_{s}$ of the machine can be expressed as

$$
P_{s}=\frac{1}{\pi} \int_{0}^{\pi} e_{s}(\omega \mathrm{t}) i_{s}(\omega \mathrm{t}) d \omega \mathrm{t}=\frac{1}{2} E_{m} I_{m}
$$

where $E_{m}$ and $I_{m}$ are the amplitudes of the no-load EMF and current, respectively. 

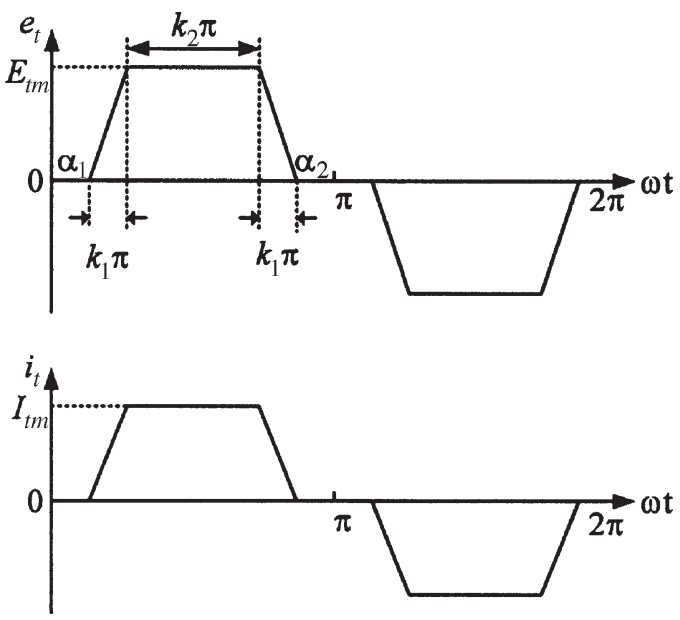

Fig. 3. Trapezoidal waveform.

For a machine with trapezoidal waveforms as shown in Fig. 3, its no-load EMF $e_{t}$ and phase current $i_{t}$ can be expressed as

$$
e_{t}= \begin{cases}0, & 0 \leq \omega \mathrm{t}<\alpha_{1} \\ \frac{E_{t m}}{k_{1} \pi}\left(\omega \mathrm{t}-\alpha_{1}\right), & \alpha_{1} \leq \omega \mathrm{t}<\alpha_{1}+k_{1} \pi \\ E_{t m}, & \alpha_{1}+k_{1} \pi \leq \omega \mathrm{t}<\alpha_{1}+\left(k_{1}+k_{2}\right) \pi \\ \frac{-E_{t m}}{k_{1} \pi}\left(\omega \mathrm{t}-\alpha_{2}\right), & \alpha_{1}+\left(k_{1}+k_{2}\right) \pi \leq \omega \mathrm{t}<\alpha_{2} \\ 0, & \alpha_{2} \leq \omega \mathrm{t}<\pi\end{cases}
$$$$
i_{t}= \begin{cases}0, & 0 \leq \omega \mathrm{t}<\alpha_{1} \\ \frac{I_{t m}}{k_{1} \pi}\left(\omega \mathrm{t}-\alpha_{1}\right), & \alpha_{1} \leq \omega \mathrm{t}<\alpha_{1}+k_{1} \pi \\ I_{t m}, & \alpha_{1}+k_{1} \pi \leq \omega \mathrm{t}<\alpha_{1}+\left(k_{1}+k_{2}\right) \pi \\ \frac{-I_{t m}}{k_{1} \pi}\left(\omega \mathrm{t}-\alpha_{2}\right), & \alpha_{1}+\left(k_{1}+k_{2}\right) \pi \leq \omega \mathrm{t}<\alpha_{2} \\ 0, & \alpha_{2} \leq \omega \mathrm{t}<\pi .\end{cases}
$$

When $e_{t}$ and $i_{t}$ are in phase, the average power $P_{t}$ of this machine is given by

$$
P_{t}=\frac{1}{\pi} \int_{0}^{\pi} e_{t}(\omega \mathrm{t}) i_{t}(\omega \mathrm{t}) d \omega \mathrm{t}=\frac{1}{3}\left(2 k_{1}+3 k_{2}\right) E_{t m} I_{t m}
$$

By using (7) and (10), the power ratio of the sinusoidal to trapezoidal DSPM generators can be obtained as

$$
\frac{P_{s}}{P_{t}}=\left(\frac{3}{4 k_{1}+6 k_{2}}\right)\left(\frac{E_{m} I_{m}}{E_{t m} I_{t m}}\right)
$$

The rms value of phase current with trapezoidal waveform can be expressed as

$$
I_{t}=\sqrt{\frac{1}{\pi} \int_{0}^{\pi} i_{t}^{2} d \omega t}=\frac{I_{t m}}{3} \sqrt{6 k_{1}+3 k_{2}}
$$

\begin{tabular}{|c|c|c|c|}
\hline Waveform & $k_{1}$ & $k_{2}$ & $P_{s} / P_{t}$ \\
\hline $120^{\circ}$ Square wave & 0 & $2 / 3$ & $\pi / \sqrt{12}$ \\
\hline Sinusoidal wave & & & 1 \\
\hline
\end{tabular}

TABLE I

Power Ratio of Sinusoidal-WaVE to SQuARE-WaVE Generators

On the other hand, the rms value of phase current with sinusoidal waveform is given by $I_{s}=I_{m} / \sqrt{2}$. Since $I_{t}=I_{s}$, the current ratio of the sinusoidal to trapezoidal waveforms can be obtained as

$$
\frac{I_{m}}{I_{t m}}=\frac{1}{3} \sqrt{12 k_{1}+6 k_{2}} .
$$

Similarly, the corresponding air-gap fluxes can be represented by the averaged no-load EMFs

$$
\left\{\begin{array}{l}
\int_{0}^{\pi} E_{m} \sin \omega \mathrm{t} d \omega \mathrm{t}=2 E_{m} \\
\int_{0}^{\pi} e_{t} d \omega \mathrm{t}=\left(k_{1}+k_{2}\right) \pi E_{t m}
\end{array}\right.
$$

Hence, the EMF ratio of the sinusoidal waveform to the trapezoidal waveform can be obtained as

$$
\frac{E_{m}}{E_{t m}}=\frac{\pi}{2}\left(k_{1}+k_{2}\right) .
$$

Substituting (13) and (15) into (11), the power ratio can be rewritten as

$$
\frac{P_{s}}{P_{t}}=\frac{\left(k_{1}+k_{2}\right) \pi}{2} \sqrt{\frac{3}{4 k_{1}+6 k_{2}}} .
$$

By taking $k_{1}=0$ and $k_{2}=2 / 3$, the trapezoidal wave becomes a square wave with a conduction angle of $120^{\circ}$. Table I compares the power ratios between the square-wave and the sinusoidal-wave DSPM generators. It can be found that the square wave generator can produce more power output (namely, additional 10.3\%) than the sinusoidal one. Therefore, the unskewed rotor is selected for this wind generator.

\section{B. Electromagnetic Analysis}

By using the FEM, the static characteristics of the proposed DSPM generator are analyzed. For simplicity, the twodimensional FEM is adopted. The corresponding nonlinear partial differential equation is expressed as

$$
\frac{\partial}{\partial x}\left(\nu \frac{\partial A_{z}}{\partial x}\right)+\frac{\partial}{\partial y}\left(\nu \frac{\partial A_{z}}{\partial y}\right)=-\left(J_{z}+J_{\mathrm{pm}}\right)
$$




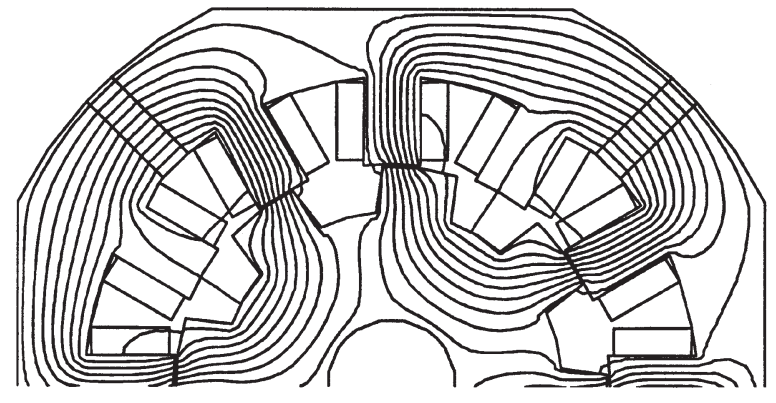

(a)

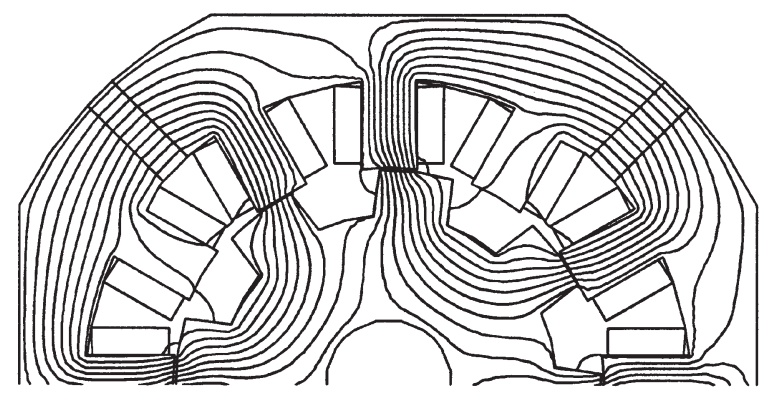

(b)

Fig. 4. Magnetic field distributions using FEM. (a) No load. (b) Full load.

where $A_{z}$ and $J_{z}$ are the $z$ components of vector magnetic potential $A$ and current density $J$, respectively; $J_{\mathrm{pm}}$ is the equivalent surface current density of PMs; and $\nu$ is the reluctivity. Both the nonlinear characteristics of the iron core and the PMs are taken into account.

The magnetic field distributions of the proposed 12/8-pole DSPM generator under no load and full load are shown in Fig. 4. It can be seen that the no-load flux distribution is mainly symmetric with only a minor distortion due to the slot effect. It can also be found that the flux is mainly concentrated at the overlapping area of the stator and rotor teeth, and the leakage flux between the PM poles is negligibly small.

Armature reaction does exist because of the bucking feature of the winding currents with respect to the field created by the PMs. Consequently, it causes a voltage drop in the machine terminal. For the proposed DSPM generator, the armature inductances are low. The corresponding armature reaction causes only a slight voltage drop. Actually, the major voltage drop is due to the armature resistance.

Similarly, by using the FEM, the flux linkages and the inductances of the proposed 12/8-pole DSPM generator can be obtained. Fig. 5 shows the PM flux linkage with respect to the rotor angle, while Fig. 6(a) shows the self-inductance characteristics with respect to both the armature current and the rotor angle.

Furthermore, the mutual inductance characteristics are shown in Fig. 6(b), where "PM - 2A" and "PM + 2A" denote the weakening and strengthening actions of the armature flux with a phase current of $2 \mathrm{~A}$ to the PM flux, respectively. It can be found that the mutual inductance depends not only on the rotor position but also on the interaction between the PM flux and the armature flux. When the armature flux strengthens the PM flux, namely flux strengthening, the corresponding

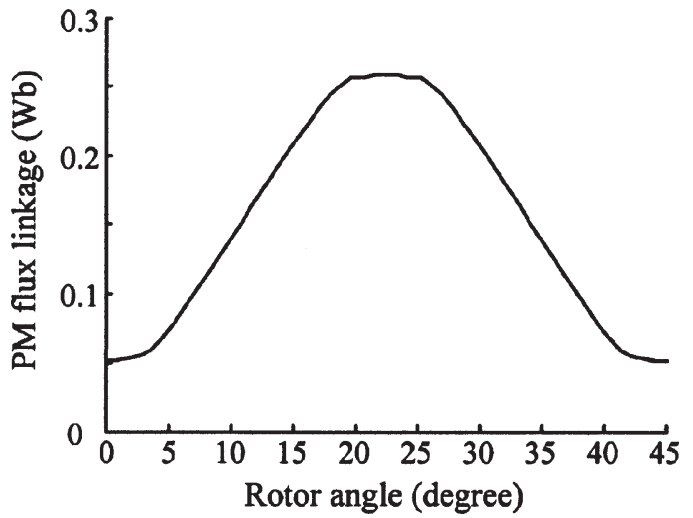

Fig. 5. PM flux linkage using FEM.

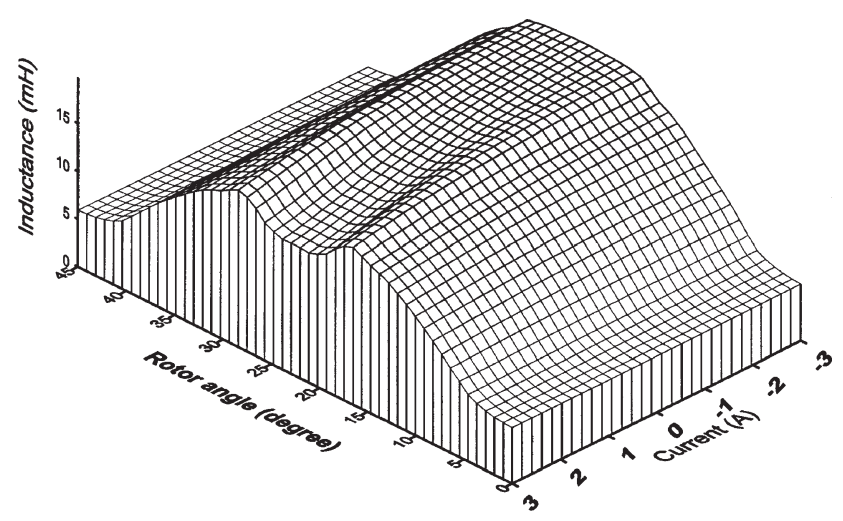

(a)

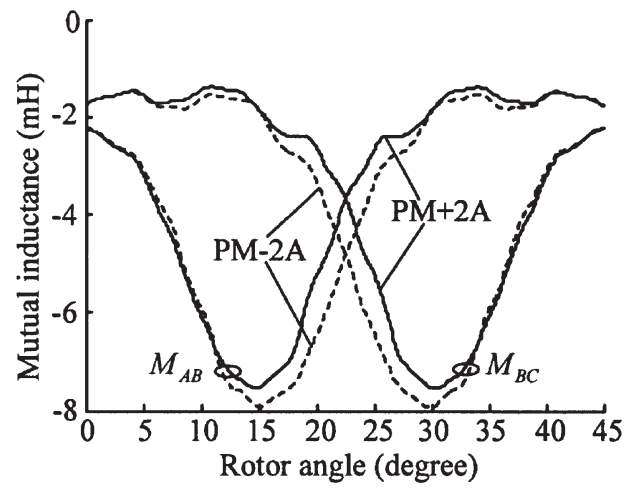

(b)

Fig. 6. Inductance characteristics using FEM. (a) Self-inductance. (b) Mutual inductance.

magnitude of the mutual inductance is smaller than that under flux weakening. This is due to the effect of magnetic saturation.

\section{System Modeling AND Simulation}

\section{A. System Modeling}

Based on the flux linkages and the inductances derived from using the FEM, the induced EMF $e$ can be calculated as

$$
e=\frac{d \psi}{d t}=u+R i
$$


where $\psi$ is the flux linkage, $u$ is the terminal voltage, $R$ is the phase resistance, and $i$ is the phase current. When the current flows from the stator winding to the external load, the flux linkage $\psi$ is expressed as

$$
\psi=\psi_{\mathrm{pm}}-L i
$$

where $\psi_{\mathrm{pm}}$ is the PM induced flux linkage, and $L i$ is the flux linkage due to armature reaction.

Therefore, the three-phase terminal voltages are given by

$$
\begin{aligned}
{\left[\begin{array}{l}
u_{A} \\
u_{B} \\
u_{C}
\end{array}\right]=} & {\left[\begin{array}{l}
\frac{d \psi_{p m A}}{d t} \\
\frac{d \psi_{p m B}}{d t} \\
\frac{d \psi_{p m C}}{d t}
\end{array}\right] } \\
& -\left[\begin{array}{ccc}
R_{A}+\frac{d L_{A}}{d t} & \frac{d M_{A B}}{d t} & \frac{d M_{A C}}{d t} \\
\frac{d M_{B A}}{d t} & R_{B}+\frac{d L_{B}}{d t} & \frac{d M_{B C}}{d t} \\
\frac{d M_{C A}}{d t} & \frac{d M_{C B}}{d t} & R_{C}+\frac{d L_{C}}{d t}
\end{array}\right]\left[\begin{array}{l}
i_{A} \\
i_{B} \\
i_{C}
\end{array}\right] \\
& -\left[\begin{array}{ccc}
L_{A} & M_{A B} & M_{A C} \\
M_{B A} & L_{B} & M_{B C} \\
M_{C A} & M_{C B} & L_{C}
\end{array}\right]\left[\begin{array}{l}
\frac{d i_{A}}{d \theta_{A}} \\
\frac{d i_{B}}{d \theta_{B}} \\
\frac{d i_{C}}{d \theta_{C}}
\end{array}\right] \omega
\end{aligned}
$$

where $u_{A}, u_{B}$, and $u_{C}$ are the phase voltages; $\psi_{p m A}, \psi_{p m B}$, and $\psi_{p m C}$ are the PM flux linkages; $R_{A}, R_{B}$, and $R_{C}$ are the resistances; $L_{A}, L_{B}$, and $L_{C}$ are the self-inductances; $M_{A B}, M_{A C}, M_{B A}, M_{B C}, M_{C A}$, and $M_{C B}$ are the mutual inductances; $i_{A}, i_{B}$, and $i_{C}$ are the phase currents; $\theta_{A}, \theta_{B}$, and $\theta_{C}$ are the rotor positions; and $\omega$ is the rotor angular velocity. The rotor positions are related by

$$
\left\{\begin{array}{l}
\theta_{B}=\theta_{A}-\alpha \\
\theta_{C}=\theta_{A}-2 \alpha
\end{array}\right.
$$

where $\alpha$ is the position difference between phases as given by

$$
\alpha=\frac{\theta_{r}}{m}=15^{\circ}
$$

where $\theta_{r}$ is the rotor-pole pitch. Moreover, the relationships of various variables among phases are given by

$$
\left\{\begin{array}{l}
\psi_{A}\left(\theta_{A}\right)=\psi_{B}\left(\theta_{B}\right)=\psi_{C}\left(\theta_{C}\right) \\
i_{A}\left(\theta_{A}\right)=i_{B}\left(\theta_{B}\right)=i_{C}\left(\theta_{C}\right) \\
u_{A}\left(\theta_{A}\right)=u_{B}\left(\theta_{B}\right)=u_{C}\left(\theta_{C}\right) .
\end{array}\right.
$$

\section{B. System Simulation}

Making use of the aforementioned system model, computer simulation is conducted to assess the performance of the DSPM generator. The Matlab/Simulink environment is adopted, since it takes the advantages of easy programming, high flexibility, and powerful toolboxes. The corresponding power-system block toolbox is particularly useful for simulation of electric machines such as the SR motor and the DSPM motor [11]. The

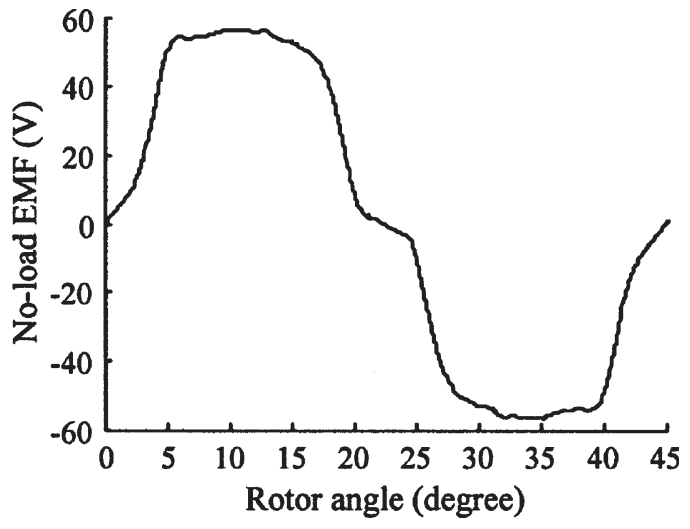

Fig. 7. Simulated no-load EMF waveform.

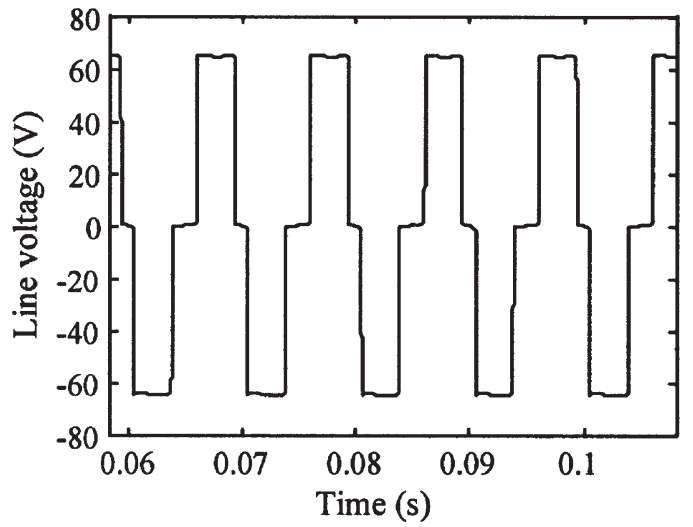

Fig. 8. Simulated line-voltage waveform.

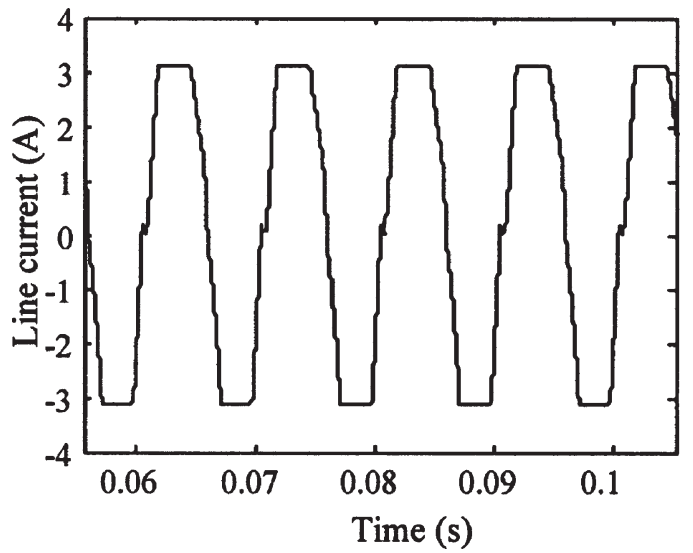

Fig. 9. Simulated line-current waveform.

no-load EMF at the rated speed of $750 \mathrm{r} / \mathrm{min}$ is simulated as shown in Fig. 7. Consequently, the line voltage, the line current, and the dc output voltage under full load at the rated speed of $750 \mathrm{r} / \mathrm{min}$ are simulated as shown in Figs. 8-10, respectively.

\section{IMPLEMENTATION AND EXPERIMENTAL VERIFICATION}

For exemplification, a low-power experimental setup is established. The proposed DSPM generator is prototyped, which confirms its high power density and robustness. The corresponding key data are listed in Table II. The natural wind 


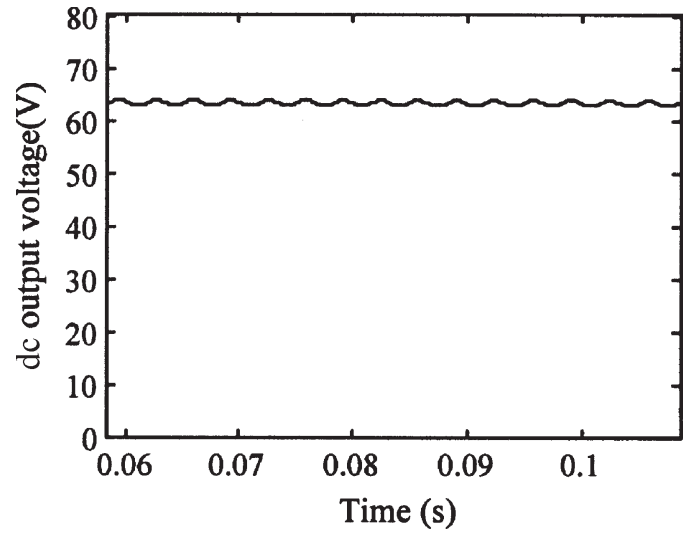

Fig. 10. Simulated dc-output-voltage waveform.

TABLE II

DATA OF PROTOTYPE

\begin{tabular}{ll}
\hline Stator inner diameter $(\mathrm{mm})$ & 75 \\
Stack length $(\mathrm{mm})$ & 150 \\
Air-gap length $(\mathrm{mm})$ & 0.45 \\
Stator pole number & 12 \\
Rotor pole number & 8 \\
Stator pole arc (degree) & 15 \\
Rotor pole arc (degree) & 20 \\
Stator pole height $(\mathrm{mm})$ & 15 \\
Rotor pole height $(\mathrm{mm})$ & 9 \\
Number of turns per phase & 260 \\
Magnet remanence $(\mathrm{T})$ & 1.08 \\
Magnet coercive force $(\mathrm{kA} / \mathrm{m})$ & 844 \\
Stator resistance per phase $(\Omega)$ & 5.47 \\
\hline
\end{tabular}

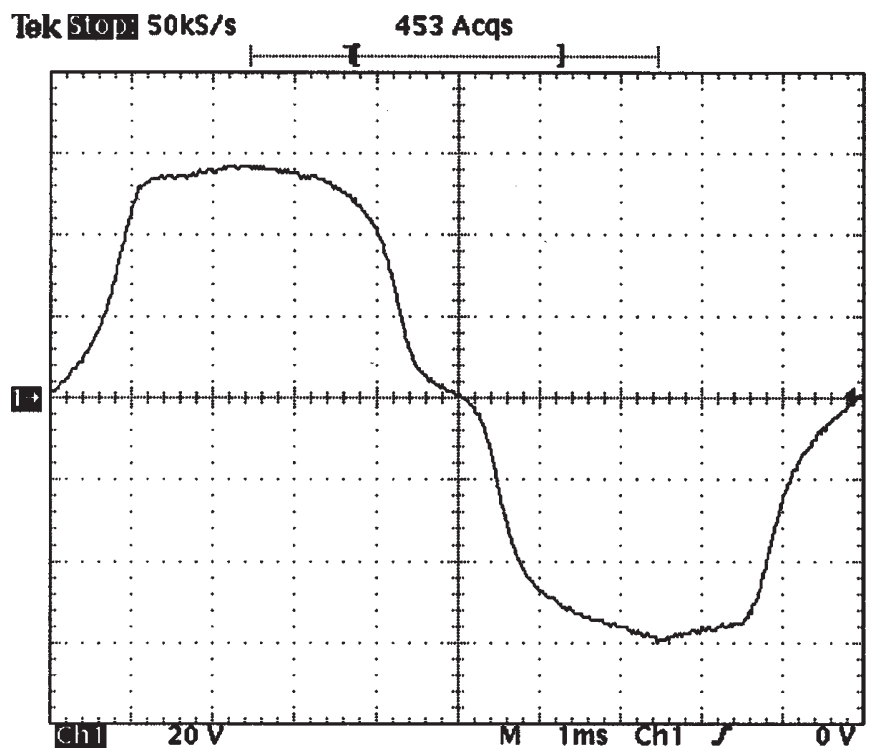

Fig. 11. Measured no-load EMF waveform (20 V/div, $1 \mathrm{~ms} /$ div $)$.

characteristics are emulated by controlling a programmable dc dynamometer in real time. Fig. 11 shows the measured no-load EMF waveform of the proposed generator operating at the rated speed of $750 \mathrm{r} / \mathrm{min}$. Fig. 12 shows the measured line voltage and current waveforms under full load at the rated speed. Fig. 13 also shows the measured dc-output-voltage waveform under full load at the rated speed. As expected, these measured waveforms closely agree with the simulation waveforms.

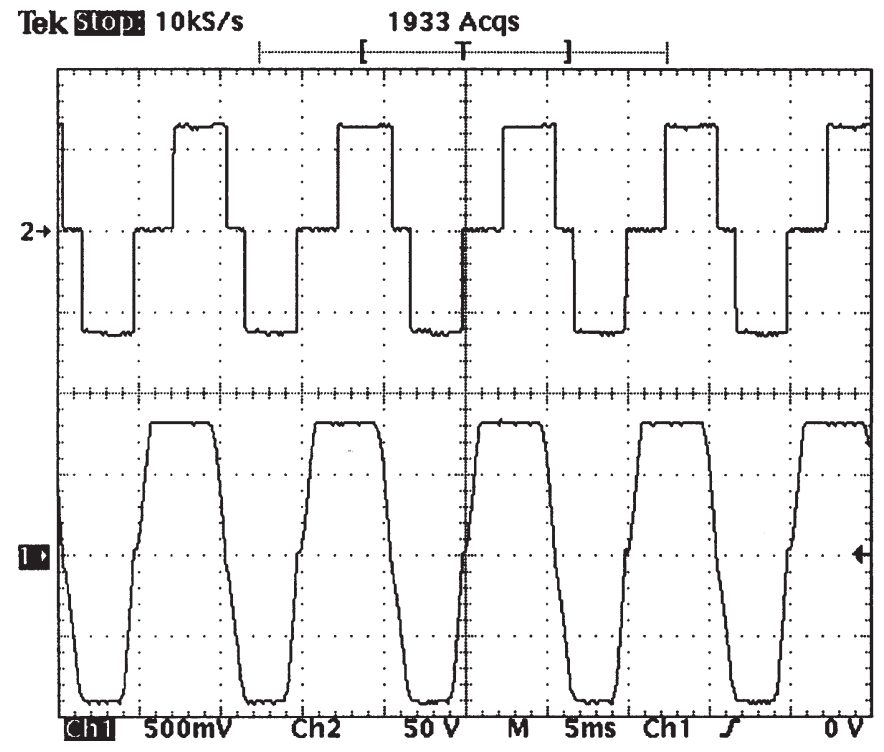

Fig. 12. Measured line-voltage and line-current waveforms (50 V/div, $2 \mathrm{~A} / \mathrm{div}$, $5 \mathrm{~ms} / \mathrm{div})$.

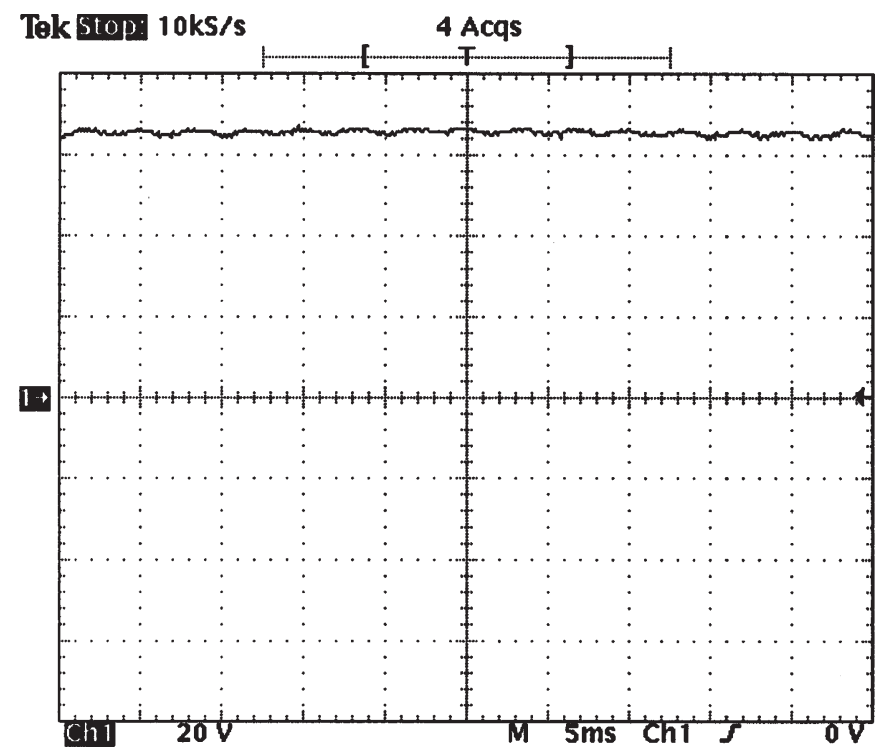

Fig. 13. Measured dc-output-voltage waveform (20 V/div, $5 \mathrm{~ms} / \mathrm{div})$.

A series of no-load tests are conducted at various rotor speeds. The measured output line voltage is compared with the simulated one as shown in Fig. 14. It can be seen that they have a good agreement. Also, the measured output voltage is almost linearly proportional to the rotor speed.

Through the three-phase rectifier, the variable output voltage of the 12/8-pole DSPM generator is rectified to a variable dc voltage. Thus, a buck converter is employed to regulate the dc-link voltage of the inverter. Considering the battery system voltage of $28 \mathrm{~V}$ as the threshold voltage of the dc link, the wind power generation directly supplies the inverter and charges the battery when the speed is over $330 \mathrm{r} / \mathrm{min}$. Otherwise, the battery supplies the inverter to produce the desired ac output. Moreover, Fig. 15 shows the measured voltage and current waveforms of the inverter ac output with the generator operating at the rated speed of $750 \mathrm{r} / \mathrm{min}$ and a resistive load of $250 \Omega$. 


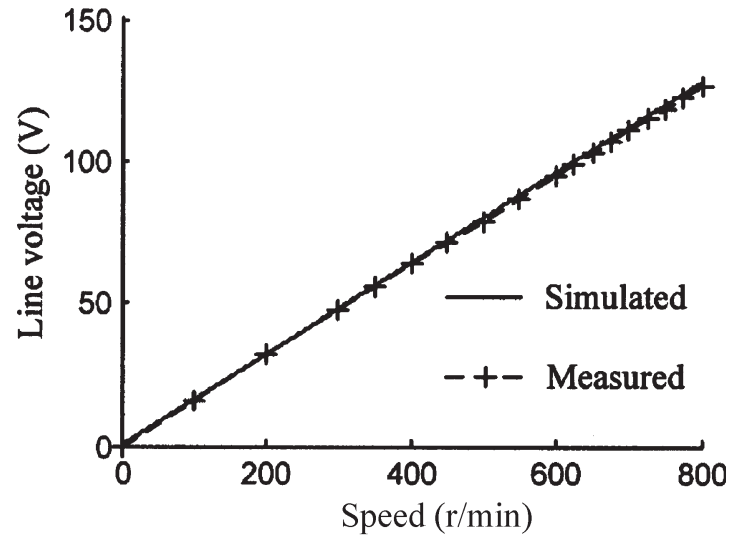

Fig. 14. Simulated and measured no-load line voltages.

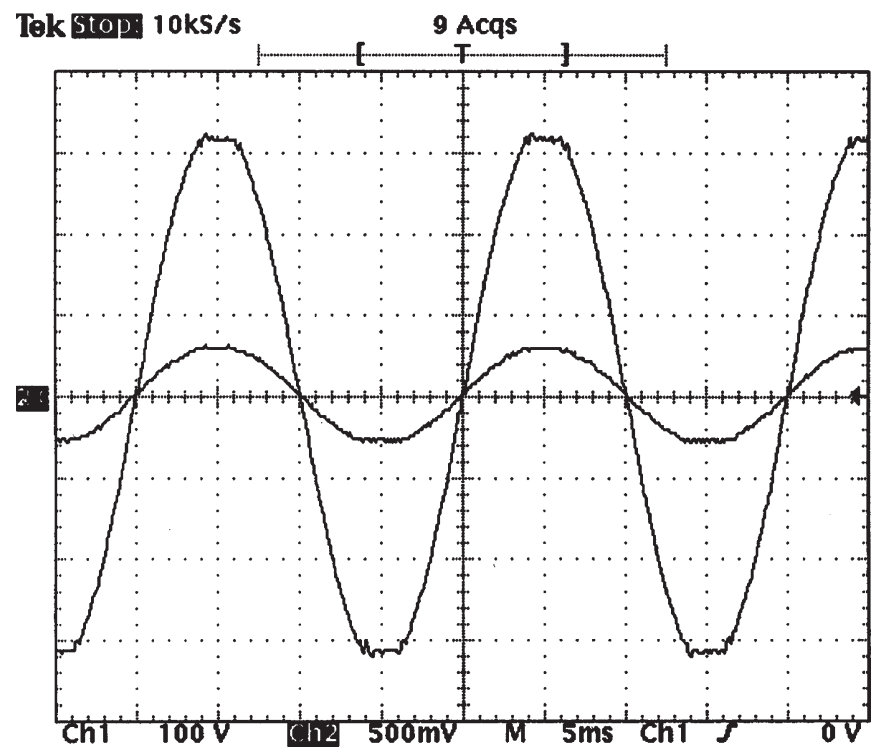

Fig. 15. Measured inverter-output-voltage and current waveforms (100 V/div, $2 \mathrm{~A} / \mathrm{div}, 5 \mathrm{~ms} / \mathrm{div})$.

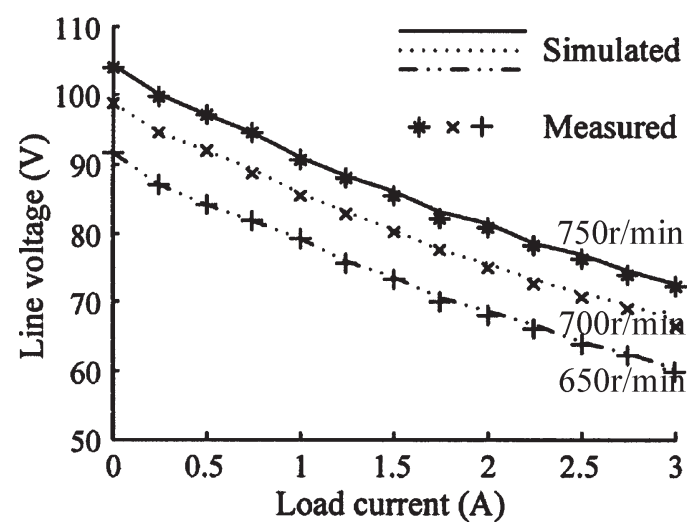

Fig. 16. Simulated and measured output-voltage regulations.

Furthermore, the voltage regulations of the whole system at different load currents and different rotor speeds are assessed as shown in Fig. 16. It is obvious that the simulated and measured results have a good agreement.

Finally, the system efficiencies at different load currents and rotor speeds are measured as shown in Fig. 17. It can be found

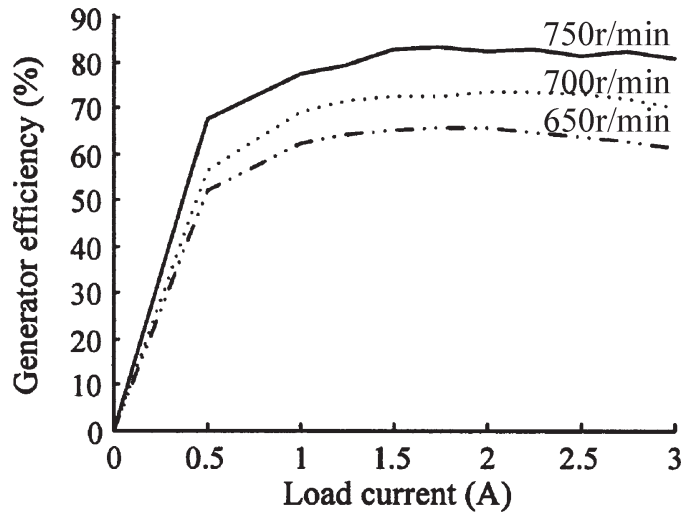

Fig. 17. Measured efficiencies.

that the efficiency can be maintained at high values over a wide range of load currents. Particularly, the efficiency under the full load of $3 \mathrm{~A}$ at the rated speed of $750 \mathrm{r} / \mathrm{min}$ is over $82 \%$.

\section{CONCLUSION}

In this paper, the design, analysis, and implementation of a new three-phase 12/8-pole DSPM generator have been presented. This DSPM generator possesses a new machine structure that can offer high power density, high robustness, and low manufacturing lost. Also, the proposed generator system can allow a high-efficiency operation over wide ranges of load current and rotor speed. Both the computer simulation and the experimental results confirm the validity of the proposed DSPM machine for wind power generation.

\section{REFERENCES}

[1] H. Chen, C. Zhang, and X. C. Zhao, "Research on the switched reluctance wind generator system," in Proc. IEEE Int. Conf. Systems, Man, and Cybernetics, Tucson, AZ, 2001, pp. 1936-1941.

[2] B. Sarlioglu, Y. F. Zhao, and T. A. Lipo, "A novel doubly salient single phase permanent magnet generator," in Proc. IEEE Industry Applications Society Annu. Meeting, Denver, CO, 1994, pp. 9-15.

[3] M. Cheng, K. T. Chau, C. C. Chan, and Q. Sun, "Control and operation of a new 8/6-pole doubly salient permanent magnet motor drive," IEEE Trans. Ind. Appl., vol. 39, no. 5, pp. 1363-1371, Sep./Oct. 2003.

[4] M. Cheng, K. T. Chau, and C. C. Chan, "Static characteristics of a new doubly salient permanent magnet motor," IEEE Trans. Energy Convers., vol. 16, no. 1, pp. 20-25, Mar. 2001.

[5] B. Sarlioglu and T. A. Lipo, "Comparison of power production capability between doubly salient permanent magnet and variable reluctance type generators," in Proc. Int. Aegean Conf. Electrical Machines and Power Electronics, Kusadasi, Turkey, 1995, pp. 1-8.

[6] _ - "Nonlinear analysis and experimental result of doubly salient PM generator," in Proc. Int. Conf. Electrical Machines and Power Electronics, Izmir, Turkey, 2001, pp. 1-6.

[7] — "Assessment of power generation capability of doubly-salient PM generator," in Proc. IEEE Int. Electric Machines and Drive Conf., Seattle, WA, 1999, pp. 549-552.

[8] _ - "Nonlinear modeling and simulation of single phase doubly salient permanent magnet generator," in Proc. IEEE Industry Applications Society Annu. Meeting, St. Louis, MO, 1998, pp. 18-26.

[9] J. Chen, C. V. Nayar, and L. Xu, "Design and finite-element analysis of an outer-rotor permanent magnet generator for directly coupled wind turbines," IEEE Trans. Magn., vol. 36, no. 5, pp. 3802-3809, Sep. 2000.

[10] M. R. Patel, Wind and Solar Power Systems. Boca Raton, FL: CRC Press, 1999.

[11] F. Soares and P. J. Costa Cranco, "Simulation of a 6/4 switched reluctance motor based on Matlab/Simulink environment," IEEE Trans. Aerosp. Electron. Syst., vol. 37, no. 3, pp. 989-1009, Jul. 2001. 


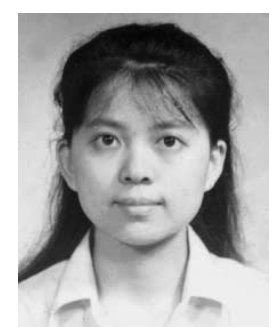

Ying Fan (S'04) received the B.Sc.(Eng.) and M.Sc.(Eng.) degrees in electrical engineering from the Department of Electrical Engineering, Nanjing University of Astronautics and Aeronautics, Nanjing, China, in 1991 and 1996, respectively. She is currently working toward the Ph.D. degree in electrical and electronic engineering at The University of Hong Kong, Hong Kong.

Her research interests focus on electric machine design, motor drive control, power electronics, modeling, and simulation.

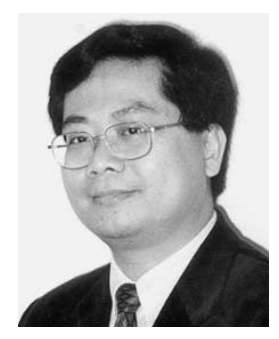

K. T. Chau (M'89-SM'04) received the B.Sc.(Eng., first-class honors), M.Phil., and Ph.D. degrees in electrical and electronic engineering from The University of Hong Kong, Hong Kong, in 1988, 1991, and 1993, respectively.

$\mathrm{He}$ is currently an Associate Professor and the Director of the International Research Center for Electric Vehicles at The University of Hong Kong. His teaching and research interests focus on three main areas-electric drives, electric vehicles, and power electronics. In these areas, he has authored or coauthored about 200 refereed technical papers and many industrial reports. He has also served as the Chair and an organizing committee member for many international conferences.

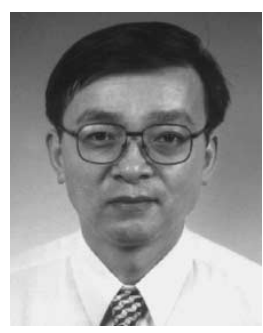

Ming Cheng (M'01-SM'02) received the B.Sc.(Eng.) and M.Sc.(Eng.) degrees in electrical engineering from the Department of Electrical Engineering, Southeast University, China, in 1982 and 1987, respectively, and the Ph.D. degree in electrical and electronic engineering from the Department of Electrical and Electronic Engineering, The University of Hong Kong, Hong Kong, in 2001.

Since 1987, he has been with Southeast University, where he is currently the Head and a Professor in the Department of Electrical Engineering. His teaching and research interests include electrical machines, motor drives, and power electronics. He has authored or coauthored of over 50 technical papers and is the holder of five patents in these areas. 